\title{
Knowledge, Attitude and Willingness of Health Care Workers Towards COVID-19 Preventive Measure in a Tertiary Health Institution in North Eastern Part of Nigeria
}

\author{
Olayinka Victor Ojo ${ }^{1,}$, , Ramsey Msheliza Yalma ${ }^{2}$, Ebenezer Obi Daniel ${ }^{3}$, Paul Olaiya Abiodun ${ }^{3}$, \\ Ahmed Mamuda Bello ${ }^{3}$, Israel Olukayode Popoola ${ }^{4}$, Christie Omolola Adams ${ }^{3}$ \\ ${ }^{1}$ Department of Physiotherapy, Federal Medical Centre, Jalingo, Taraba State, Jalingo, Nigeria \\ ${ }^{2}$ Department of Community Medicine, University of Abuja, Federal Capital Territory, Abuja, Nigeria \\ ${ }^{3}$ Department of Public Health, School of Public Health, Texila American University, Georgetown, Guyana \\ ${ }^{4}$ Departmrnt of Epidemiology and Community Health, Faculty of Clinical Sciences, College of Medicine, University of Ilorin, Ilorin, Nigeria
}

Email address:

olayinkaojo43@yahoo.com (O. V. Ojo)

${ }^{*}$ Corresponding author

\section{To cite this article:}

Olayinka Victor Ojo, Ramsey Msheliza Yalma, Ebenezer Obi Daniel, Paul Olaiya Abiodun, Ahmed Mamuda Bello, Israel Olukayode Popoola, Christie Omolola Adams. Knowledge, Attitude and Willingness of Health Care Workers Towards COVID-19 Preventive Measure in a Tertiary Health Institution in North Eastern Part of Nigeria. Central African Journal of Public Health. Vol. 6, No. 5, 2020 , pp. $251-255$. doi: 10.11648/j.cajph.20200605.13

Received: August 13, 2020; Accepted: August 24, 2020; Published: September 10, 2020

\begin{abstract}
Covid-19 outbreak has been a great public health challenge to the world where government in various countries has made drastic effort to mitigate the outbreak of the pandemic "COVID-19" by imposing lockdown, movement control. Adherence to control measure is affected by their knowledge, attitude and willingness towards covid-19 preventive measure. In this study, to assess the knowledge, attitude and willingness towards covid-19 preventive measure among the healthcare workers in a tertiary health institution in North Eastern part of Nigeria. Method: A descriptive cross sectional survey was performed in a tertiary health institution in North Eastern part of Nigeria between May and July 2020. Data were obtained through the use of structured questionnaire, which was subjected to a pilot study for validation of the main study. Summated scores were used to grade respondents who are healthcare workers on their knowledge, attitude and willingness towards covid19 preventive measures. Data were presented in using descriptive analysis and inferential status was used to test for the association between various characteristics and their knowledge, attitude and willingness of healthcare workers toward covid19 preventive measures. Result: The result showed that (37.5\%) of the 127 respondent has good knowledge on covid-19 and (93.6\%) has positive attitude and willingness toward covid-19 preventive measure. It was further revealed that there was a statistical significant association between occupation out of all the demographic variables and the knowledge, attitude and willingness toward covid-19 preventive measure. Conclusion: Most of the healthcare workers had good knowledge, attitude and willingness toward covid-19 preventive measure. Additional educative interventive strategies are to be adopted by the hospital/health ministry for health workers to improve their knowledge on communicable disease.
\end{abstract}

Keywords: Covid-19, Knowledge, Attitude and Willingness, Healthcare Workers, Allied Health Workers

\section{Introduction}

Outbreak of Novel Coronavirus Disease (covid-19) is a global health emergency which is an infectious condition that spread directly or indirectly from person to person and causes respiratory illness ranging from common cold to acute respiratory syndrome [1]. The outbreak was first identified in the city capital of Hubei originate from Wuhan, China, Dec 2019. According to World Health Organization, covid-19 is a serious public health concern and has a high risk for severe illness and spreading rapidly all over the world. Historically, evidence has shown that the virus is transmitted through bird and animals with human being particularly vulnerable to infection and 
transmission of the virus [2]. This disease was described as a pandemic by World Health Organization Director General [3]. The world infection rate counts at 14,684,741 confirmed cases with active case at 3,082,252 having 610,110 death and (27.21\%) recovered [4]. Most of the death occurred in patients above 50 years of age followed by children and majority of those infected are within the ages of 20 to 47 years. Confirmed cases which included both laboratory and clinically diagnosed till now has no specific anti-viral treatment recommended and there are no vaccine currently [5].

There are now more than 625,818 confirmed cases in which 297,291 are active, 13762 death and 314,763 recoveries of coronavirus across Africa with a number of African countries imposing range of prevention and containment measures against the spread of the pandemic. According to the latest data by John Hopkins University and Africa Centre for Disease Control on covid-19 in Africa, the whole of Africa has rising case [6]. In Africa, South Africa has the highest number of confirmed infected cases as of july 2020 based on world health organization data; the index case was reported and confirmed in Nigeria who is an Italian citizen on the $27^{\text {th }}$ February, 2020. Government declared a total closure of Nigeria airports and seaport including various land borders with neighbouring countries to curtail further importation of the virus and later place lockdown on the three major prone area in the country ordering people to stay at home with public enlightenment on preventive measure to take in preventing the spread of the virus [9].

Nigeria centre for disease control confirmed 36,663 cases in which 20,769 are active, 15,105 recoveries and 789 deaths with about 800 health worker infected. All states and the Federal Capital Territory have recorded cases of the virus and Taraba state where the study is carried out has 19 cases as at the time of this study [10]. The fact that currently there is no treatment or vaccine, the novel coronavirus prevention is not only the best but the sole alternative in battling the pandemic [8]. Government action in introduction of regulations that limit the contact between people to prevent transmission could be the most realistic solution in hauling the spread of virus [11]. However, people's response to those regulation reflect in their level of compliance and perception of the seriousness of the problem, is the determinant factor in health authorities struggle in containing the pandemic. Regular washing of hand and staying home, use of face mask, observation of social distancing, coughing in a tissue paper and disposing it immediately or coughing under one's elbow are the paramount preventive measures in fighting covid-19 [11]. Other strategies focusing on isolation of confirmed cases, infection control diagnosis and the provision of clinical care for infected people. Precaution should be adopted by health care workers during specimen collection and care. Health care workers are at high risk of getting the infection in which many health care workers tested positive to the virus a $d$ the source of transmission in the community [12].

Some previous studies showed that HCW's lacked knowledge, attitude and willingness towards preventive measure [13]. Federal Medical Centre Jalingo being the largest tertiary health institution in Taraba State Nigeria with specialist services so the response to major medical issues are available to all patients, as well as supporting the HCWs to treat the suspected cases of covid-19 infection in FMC jalingo. Due to the importance of this facility and evidence obtained from Lagos State and Kano State couple with the recent incidence of $\mathrm{HCW}$ infection in the site of study, HCWs were at a a high risk of getting the virus within medical faculties and also transmission to other patients within medical facilities and also transmission to other persons within the community.

This study is aimed to assess THE KNOWLEDGE, ATTITUDE AND WILLINGNESS TOWORDS COVID-19 PREVENTIVE MESSURE AMONG HCWs at Federal Medical Centre Jalingo, Taraba State. The findings will help authorities organize the necessary education programs in order to provide up to date information and deliver the best practice to control covid-19 disease.

\section{Methodology}

A descriptive cross sectional study design was adopted in this study which was carried out between May and July 2020 was to assess the knowledge, attitude and willingness of healthcare workers HCWs towards COVID-19 preventive measures. A systemic random sampling was adopted in recruiting participant who are HCWs in Federal Medical Centre Jalingo including doctors, nurses, allied health workers (pharmacist, physiotherapists, laboratory scientists, nutritionists, radiographer, technical staff) were evaluated as eligible participants in this study.

A structured questionnaire, subjected to a pilot study for validation before the main study, reviewed by research expert for more scientific impact. Each correct knowledge on covid19 was given. One point while incorrect answers were given zero points. Each correct answer in relation to the knowledge of covid-19 was given a point. The total knowledge score of HCWs varied between zero (0) and ten (10) and cut off level of $>/ 7$ indicate good knowledge. The score on attitude and willingness varied between zero (0) and seven (7) cut off level of $<4$ was evaluated as negative attitude and willingness while $</ 4$ was evaluated as $>/$ positive attitude and willingness. The variable and measurement collected included socio-demographic data. Knowledge of covid-19, attitude and willingness toward covid-19 preventive measure. Data analysis was done using chi square and analysis of variance was carried out. All result was set at 0.05 level of significant. All eligible $\mathrm{HCW}$ were informed about the objective of the study and they agreed and signed consent form before participation.

\section{Result}

Out of the 150 (one hundred and fifty) structured questionnaire, 127 (one hundred and seven) with valid response was obtained representing $85 \%$ response rate. The mean age of $(28.1+-6.1)$ years, $(34 \%)$ were female, the 
highest percentage of HCWs were nurses (27\%) and majority of them has less 5 years of experience $(62.9 \%)$ (Table 1$)$. As shown in Table 2 most of the respondents are aware that covid-19 is a virus $(99.1 \%)$ and the mode of transmission is by close contact with infectious person $(76.0 \%)$. However, $(98.2 \%)$ of the respondent knew that washing of hands with soap and water, use of face mask and practicing physical distance. The overall response to the study was good, the respondent that has good knowledge were $(87.5 \%)$. The result on attitude as revealed in table 3 shows that $(93.6 \%)$ of respondent has positive attitude towards covid-19 prevention among healthcare workers were presented in table 4 in which profession is significantly associated with the knowledge, attitude and willingness towards covid-19 preventive measures $\mathrm{p}<0.05$.

Table 1. Socio-demographic characteristics of health workers [n (\%)].

\begin{tabular}{|c|c|}
\hline Characteristics & $n=127 \%$ \\
\hline Age & Frequency n (\%) \\
\hline $20-29$ & $73(57.2)$ \\
\hline $30-49$ & $43(33.9)$ \\
\hline $50-59$ & $11(8.9)$ \\
\hline Sex & Frequency n (\%) \\
\hline Male & $58(46 \%)$ \\
\hline Female & $69(54 \%)$ \\
\hline Profession & Frequency n (\%) \\
\hline Doctor & $19(15)$ \\
\hline Nurse & $34(27)$ \\
\hline Allied Health Workers & $63(49.6)$ \\
\hline Years of experience & Frequency n (\%) \\
\hline$<-5$ & $80(62.9)$ \\
\hline $5-10$ & $39(30.8)$ \\
\hline$>10$ & $8(6.3 \%)$ \\
\hline
\end{tabular}

Table 2. Knowledge of healthcare workers towards covid-19.

\begin{tabular}{|c|c|c|}
\hline Questions & Correct Answers n (\%) & Wrong Answers n (\%) \\
\hline Covid-19 is a virus infection & $126(99.1)$ & $1(0.9)$ \\
\hline Covid-19 is transmitted by close contact with infected person & $85(67.0)$ & $42(33)$ \\
\hline Fever, cough, sore throat and shortness of breath are symptoms & $92(72.81)$ & $35(27.2)$ \\
\hline $\begin{array}{l}\text { Washing of hands with soap and water and use of face mask and practicing social distance help in } \\
\text { preventing covid-19 }\end{array}$ & $125(98.2)$ & $2(1.8)$ \\
\hline Covid-19 is a world pandemic & $126(99.1)$ & $1(0.9)$ \\
\hline Compliance with social distancing help in covid-19 prevention & $113(88.7)$ & $14(11.3)$ \\
\hline Coughing in a tissue paper or under one's elbow reduce covid-19 transmission & $110(86.7)$ & $17(13.3)$ \\
\hline Avoiding crowded areas are helpful in reducing covid-19 transmission & $99(78.2)$ & $28(21.8)$ \\
\hline $\begin{array}{l}\text { Prompt report to a medical doctor when symptoms like fever, high temperature are observed are useful in } \\
\text { reducing covid-19 transmission }\end{array}$ & $97(76.6)$ & $30(23.4)$ \\
\hline
\end{tabular}

\begin{tabular}{ll}
\hline Sources of covid-19 information & $\mathbf{n}(\mathbf{\%})$ \\
\hline Television & $101(79.2)$ \\
Social media & $116(91.1)$ \\
Hospital/health ministry website & $105(82.6)$ \\
Health journals & $55(43.4)$ \\
\hline
\end{tabular}

Knowledge towards covid-19

\begin{tabular}{ll}
\hline Mean \pm SD & $\mathbf{7 . 6 1 \pm 1 . 4 5}$ \\
\hline Good knowledge & $111(87.5 \%)$ \\
Poor knowledge & $16(12.5 \%)$ \\
\hline
\end{tabular}

Table 3. Attitude and willingness of health worker towards covid-19.

\begin{tabular}{lll}
\hline Attitude of healthcare workers towards covid-19 & Yes n (\%) & No n (\%) \\
\hline I always wash my hands with soap and running water at interval & $105(82.3)$ & $22(17.7)$ \\
I keep social distance & $101(79.8)$ & $26(20.2)$ \\
I usually cough or sneeze in a tissue or under my elbow & $124(97.9)$ & $3(2.1)$ \\
I sanitize my hands with alcohol based sanitizer & $118(92.7)$ & $9(7.3)$ \\
Do you protect yourself using face mask & $125(98.7)$ & $2(1.3)$ \\
\hline
\end{tabular}




\begin{tabular}{ll}
\hline Attitude (mean \pm SD) & $\mathbf{1 . 8 5} \pm \mathbf{0 . 3 7}$ \\
\hline Good attitude & $118(93.3 \%)$ \\
Poor attitude & $9(6.7 \%)$ \\
\hline
\end{tabular}

Table 4. Association between respondent characteristics and knowledge towards covid-19 CHARACTERISTICS.

\begin{tabular}{|c|c|c|c|c|}
\hline Knowledge Age & Knowledge Good \% & Knowledge Poor\% & Chi square & Pvalue \\
\hline $20-29$ & 56 & 1 & & \\
\hline $30-49$ & 24 & 19 & 27.091 & 0.300 \\
\hline $50-59$ & 10 & & & \\
\hline Sex & Good & Poor & Chi square & Pvalue \\
\hline Male & 46 & 12 & \multirow{2}{*}{18.231} & \multirow{2}{*}{0.740} \\
\hline Female & 58 & 11 & & \\
\hline Profession & Good & Poor & Chi square & Pvalue \\
\hline Doctors & 17 & 2 & \multirow{3}{*}{17.436} & \multirow{3}{*}{0.001} \\
\hline Nurses & 31 & 3 & & \\
\hline Allied health Workers & 68 & 6 & & \\
\hline Years of experience & Good & Poor & Chi square & P value \\
\hline$>5$ & 66 & 14 & \multirow{3}{*}{15.061} & \multirow{3}{*}{0.325} \\
\hline $5-10$ & 32 & 7 & & \\
\hline$>10$ & 7 & 1 & & \\
\hline \multicolumn{5}{|c|}{ Association between respondent characteristics attitude and willingness. } \\
\hline Age & Good & Poor & Chi square & Pvalue \\
\hline $20-29$ & 63 & 16 & \multirow{3}{*}{9.061} & \multirow{3}{*}{0.151} \\
\hline $30-49$ & 35 & 8 & & \\
\hline $50-59$ & 10 & 1 & & \\
\hline Sex & Good & Poor & Chi square & Pvalue \\
\hline Male & 47 & 11 & \multirow{2}{*}{7.320} & \multirow{2}{*}{0.129} \\
\hline Female & 49 & 20 & & \\
\hline Profession & Good & Poor & Chi square & Pvalue \\
\hline Doctors & 16 & 3 & \multirow{3}{*}{23.145} & \multirow{3}{*}{0.001} \\
\hline Nurses & 30 & 4 & & \\
\hline Allied health workers & 70 & 4 & & \\
\hline Year experience & Good & Poor & Chi square & P value \\
\hline$<5$ & 71 & 9 & \multirow{3}{*}{5.621} & \multirow{3}{*}{0.453} \\
\hline $5-10$ & 34 & 5 & & \\
\hline$>10$ & 6 & 2 & & \\
\hline
\end{tabular}

\section{Discussions}

Since the inception of covid-19 pandemic, Taraba State only recorded 19 cases in which all of them were treated at the isolation centre and discharged with 1 case still under isolation and the centre has not recorded any mortality as at the period of this study while there has been no reported case of covid-19 among health workers. Healthcare workers are seen to have an increased risk to infection if their knowledge, attitude and willingness toward covid-19 prevention method is poor.

The findings in this study reveal that healthcare workers had a level of knowledge and positive attitude towards covid19 preventive measures. It was observed that most of the respondents got the information on covid-19 through varieties of media sources such as television, social media, health journal, hospital/health ministry website supported by [15]. This study finding indicates that social media serves as the main sources of information for healthcare workers on emergence of infectious disease like covid-19 compared to the hospital/health ministry website as at the time of this study which is a very crucial issue for the government to update varieties of means/source to improve the knowledge and learning materials about this pandemic. It is also important to upgrade the public health/community health department of every tertiary hospital so as to respond to any epidemic/pandemic by giving out detailed information for the community in possible symptoms and the way of prevention of the transmission [16] but with little variation with a study in US [17].

Another important finding was that majority of the respondents has a positive attitude and willingness towards covid-19 preventive measure. It was also observed that 
profession was significantly associated with the knowledge, attitude and willingness which were disclosed in other studies [16].

\section{Conclusion}

The finding shows that most of the healthcare workers in Federal Medical Centre Jalingo had good knowledge and positive attitude and willingness towards covid-19 preventive measure than expected. Further studies could estimate the knowledge, attitude and willingness of healthcare workers towards covid-19 on a larger scale to be able to design appropriate intervention at the national level.

\section{Recommendation}

Additional educational intervention and campaign are require for healthcare workers to avail them the knowledge of the mode of transmission, treatment strategies, as well as the risk of personal and community infection with covid-19 and government / hospital management should provide enough protective apparel for health worker and a tangible life insurance scheme for health workers.

\section{References}

[1] Chen Y, Liu Q and Guo D. (2020). Emerging coronavirus. Genome structure replication and pathogenesis J med virol 92 (4) $418-423$.

[2] Schoeman D, Fielding B. C. Coronavirus protein current knowledge Virol J 2019: 19 (1): 69.

[3] World Health Organization WHO Director-General's opening remark at media briefing on covid-19. march 2020.

[4] Huffington, A and Williams M 2020. Fortune media IP Limited Retrived from https:/forlin.com/2020/03/11 coronavirus-health care workers well being.
[5] Africa news on health, coronavirus, Africa $24^{\text {th }}$ April 2020.

[6] Africa centre for disease control, update on covid-19 cases in Africa $24^{\text {th }}$ April 2020-07-10.

[7] Heymann D, L, Shindo N. Covid-19: what is next for public health? The lancet 2020; 395 (10224): 542-543. Doi 10.1016Is 0140-6736(20)30374-3.

[8] Nigeria centre for disease control (NCDC) report on $20^{\text {th }}$ April 2020.

[9] Covidusualyer.com.

[10] Lee VJ, Chiew CJ, Khong WX. Interrupting transmission of covid-19 lessons from containment effort in Singapore. Journal of travel medicine 2020 (online first). Doi $10.1093 / \mathrm{stm} / \mathrm{tssa} 039$.

[11] Federal Ministry of Health update 22 ${ }^{\text {nd }}$ April 2020.

[12] Deng J. F, Olowokure B, Kaydos-Daniel S. C, Cheng H. J, Berwick R. S, et al severe acute respiratory syndrome (sars): knowledge, attitude, practices and sources of information among physician ensuring a SARS fever hotline service. Public health 2009; 1200): 15-19.

[13] Ahmed M. H, Rehab H. E, Mahdi A. A. knowledge and attitude towards middle east respiratory syndrome-coronavirus (MERS-COV) among health care works in South Western Saudi Arabia. East- meditter Health J 2019 doi https://doi; org/10,267/emly.19.079.

[14] Albarrk A. L, Mohammed R, Al Elayan A, Al Fawaz et al middle East. Respiratory Syndrome (MERS): comparing the knowledge, attitude and practice of different healthcare workers J infect public health 2019, doi 10.1016/J.Jiph, 2019.06.029.

[15] Bener A, Al-Khal A. knowledge, attitude and practices toward SARS J. R soc promot Health 2004: 167-170.

[16] Phan L. T, Ngguyen TV, Luong Q. C et al Importation and human to human transmission of a novel coronavirus in Vietnam N Eng J Med 2020, 382 (9): 872-874. 